\title{
POUR UNE RELECTURE DES COLLECTIONS ARCHÉOLOGIQUES NÉOLITHIQUES ET CHALCOLITHIQUES DANS LA ZONE DE HAMANGIA-BAIA: NOUVELLES DONNÉES CHRONOLOGIQUES RELATIVES AUX RECHERCHES CONDUITES PAR DUMITRU BERCIU
}

\author{
LAURENT CAROZZA, \\ CRISTIAN MICU, \\ ADRIAN BĂLĂȘESCU, \\ SORIN AILINCĂI, \\ ALBANE BURENS, \\ OANA GÂZA, \\ CRISTIAN MĂNĂILESCU
}

\section{RÉSUMÉ:}

Entre 1952 et 1961, Dumitru Berciu réalise de nombreuses recherches de terrain dans la zone littorale du lac Golovița, sur la zone des communes actuelles de Baia et de Ceamurlia de Jos (département de Tulcea). Il publiera en 1966 une partie des fouilles conduites sur les habitats de Baia-Golovița et Ceamurlia de Jos. Dans le même intervalle de temps, Dumitru Berciu va réaliser des fouilles dans le village même de Baia, sur le tell de „Boruz”. En 2019, dans le cadre d'un projet de l'Académie Roumaine, un collectif Franco-Roumain a engagé la revisite des collections et des archives conservées à l'Institut d'archéologie „Vasile Pârvan“. Ce travail, encore en cours, permet de jeter un exposant nouveau regard sur le peuplement de la zone littorale de l'actuel lac Golovița entre le $6^{\mathrm{e}}$ millénaire et le $5^{\mathrm{e}}$ millénaires avant notre ère. L'analyse des archives et des prospections de terrain nous ont permis de localiser avec précisions les trois sites, et notamment le tell de „Boruz”, pour lequel nous ne disposons d'aucune archive écrite, mais seulement des ensembles mobiliers conservés à Bucarest. L'objet de cet article est de présenter un bilan d'étape, et, au vu des premières datations radiocarbone obtenues, d'évaluer les hypothèses émises par Dumitru Berciu quant à l'antériorité de l'établissement de Baia-Golovița sur celui de Ceamurlia de Jos. Un autre enjeu est de proposer une relecture, malgré l'absence d'archives, de la stratigraphie du tell Chalcolithique Gumelnița de „Boruz”.

REZUMAT: REANALIZAREA COLECȚIILOR ARHEOLOGICE NEOLITICE ŞI CALCOLITICE DIN ZONA HAMANGIA - BAIA: NOI DATE CRONOLOGICE REFERITOARE LA CERCETĂRILE REALIZATE DE DUMITRU BERCIU

Între 1952 şi 1961, Dumitru Berciu a realizat numeroase cercetări arheologice în zona lacului Golovița, pe teritoriul actual al comunelor Baia și Ceamurlia de Jos (jud. Tulcea). După finalizarea acestora, în anul 1966 a fost publicată o parte a săpăturilor din aşezările atribuite culturii Hamangia de la Baia-Golovița și Ceamurlia de Jos. În acelaşi interval de timp, Dumitru Berciu a condus săpăturile de pe tell-ul localizat în marginea de vest a satului Baia (tell-ul „Boruz”). În anul 2019, ca parte a unui proiect al Academiei Române, un colectiv franco-român a propus o reanalizare a colecțiilor și arhivelor păstrate la Institutul de Arheologie „Vasile Pârvan” din București. Această activitate, încă în desfăşurare, ne va permite în primul rând să aruncăm o nouă privire asupra aşezărilor din zona lacului Golovița din perioada mileniilor VI și V î.e.n. Analiza arhivelor și cercetărilor de teren ne-a permis să localizăm cu precizie cele trei aşezări mai sus menționate, în special tell-ul de la Baia, pentru care nu exista o documentație scrisă, ci doar o parte din materialele păstrate la București. Scopul acestui articol este să prezinte un raport de etapă și, având în vedere primele datări radiocarbon obținute, să evalueze ipotezele înaintate de Dumitru Berciu cu privire la anterioritatea sitului de la Baia-Golovița față de cel de la Ceamurlia de Jos. O altă provocare este aceea de a propune o relectură a stratigrafiei așezării-tell de la Baia, în contextul absenței documentelor de arhivă. 
MOTS CLÉS: Chalcolithique, Hamangia, Gumelnița, habitat, tell, Dobroudja, lagune, datation radiocarbone, chronologie.

CUVINTE CHEIE: Calcolitic, Hamangia, Gumelnița, locuință, tell, Dobrogea, lagună, datare radiocarbon, cronologie.

\section{Le contexte de la recherche}

Dans le cadre de la mission archéologique franco-roumaine „Archéologie du delta du Danube” et du Laboratoire International Associé (IRP GOCHE), nous avons entrepris de travailler sur la caractérisation de la séquence chronologique et culturelle Néolithique-Chalcolithique en Dobroudja du nord. Ces travaux visent, notamment, à reprendre l'étude des collections anciennes, et à les publier de manière monographique. Depuis 2012, les travaux ont essentiellement porté sur la culture de Gumelnița, avec l'étude des sites de Carcaliu et Trestenic. Plus récemment, nous avons engagé l'étude des collections issues des fouilles de Dumitru Berciu sur le tell de Baia (Fig. 1). Cette analyse a donné lieu à une première publication des industries lithiques ${ }^{1}$. Ces études viennent compléter des recherches de terrain, notamment sur les tells de Luncavița et de Taraschina ${ }^{2}$, mais également des approches paléo-géographiques et paléo-environnementales autour du tell de Lunca ${ }^{3}$.

\subsection{Problématique}

D'un point de vue historique, la transition Néolithique constitue une période fondamentale durant laquelle l'Homme modifie ses relations avec l'environnement pour établir, selon des modalités diversifiées, une économie fondée sur l'élevage et l'agriculture. Les voies d'approche de ce processus sont extrêmement variées puisque c'est bien l'ensemble des composantes de l'anthroposystème qui se trouve modifié. En Europe, l'étude de la néolithisation s'inscrit dans une analyse des vecteurs de diffusion (diffusion culturelle vs diffusion démique par migration de population depuis le Proche-Orient d'où est originaire une grande partie des espèces animales et végétales domestiques). Dans ce contexte, les études archéologiques, et notamment l'analyse de la culture matérielle (matières premières, chaînes opératoires, fonctions des outillages et des ustensiles...), permettent une approche des rythmes d'émergence des nouveautés techno-économiques néolithiques (en fonction d'un milieu environnemental ou social plus ou moins favorable).

La question de l'émergence du Chalcolithique Européen, considéré comme une étape majeure de l'apparition des sociétés complexes, est au centre des recherches ${ }^{4}$. Si les travaux récents ont plus particulièrement portés sur les cultures du $5^{\mathrm{e}}$ millénaire avant notre ère de Varna et de Gumelnița (du complexe culturel Kodjadermen-GumelnițaKaranovo VI du $5^{\mathrm{e}}$ millénaire avant notre ère), il s'avère aujourd'hui nécessaire de prendre en compte la genèse du phénomène de l'émergence du Chalcolithique. Les travaux pionniers de Dumitru Berciu ont permis, dans les années 1950, de montrer l'originalité et le rôle majeur de la culture de Hamangia dans ce processus. On rappellera la contribution majeure à cette problématique que constitue la publication de l'ouvrage de Dumitru Berciu, en 1966, Cultura Hamangia. Cette publication montre que la zone de l'actuel delta du Danube et du littoral de la mer Noire constitue un creuset pour l'émergence des sociétés complexes durant le $5^{\mathrm{e}}$ millénaire avant notre ère.

Si des fouilles récentes participent au renouvèlement des données ${ }^{5}$, les collections issues des fouilles de Dumitru Berciu demeurent encore, pour partie, inédites ou partiellement étudiées. La qualité des fouilles conduites par ce chercheur - malgré les biais induits par les méthodes d'investigation mises en œuvre à dans les années 1950 - nous autorise aujourd'hui reprendre l'étude des données de terrain. Au-delà de la nécessité de réaliser la base iconographique et les inventaires de ces collections, notre objectif est de mettre en œuvre des méthodes modernes, et notamment des études technologiques et archéométriques, de manière à poursuivre le travail engagé par Dumitru Berciu.

\footnotetext{
$\overline{{ }^{1} \text { Mihail, Ștefan } 2014 .}$

${ }^{2}$ Carozza, Bem, Micu 2011.

${ }^{3}$ Carozza et al. 2014.

${ }^{4}$ Guilaine 2007.

5 Micu 2006; Bălășescu 2008; Radu 2008; Voinea 2010a; Voinea 2010b; Voinea, Dobrinescu 2003; Voinea, Neagu 2006; Voinea, Neagu 2008; Voinea et al. 2007; Voinea, Neagu, Radu 2009; Voinea, Grigoruță, Carpuș 2014; Tornero et al. 2013; Balasse et al. 2014.
} 


\subsection{Méthode}

L'objectif central de notre projet réside dans la mise en œuvre d'une relecture des ensembles archéologiques fouillés par Dumitru Berciu ${ }^{6}$ sur les sites de Ceamurlia de Jos et de Baia-Golovița. Il s'agit de prolonger les études anciennes en développant principalement des approches technologiques et archéométriques, susceptibles de caractériser les structures économiques, technologiques et culturelles de ces premières communautés agropastorales riveraines du littoral de la mer Noire. En préalable à la conduite de ces analyses, il conviendra de réaliser une base de données des matériels disponibles dans les archives de l'Académie Roumaine et dans les réserves archéologiques. Il s'agira de rééquilibrer les acquis et d'homogénéiser le cadre archéologique par une remise à niveau documentaire (création d'une base de données, reprise de l'iconographie, quantification des mobiliers). L'autre objectif est de maîtriser et d'affiner les temporalités dans le but d'observer la dynamique spatiale et temporelle. Il faudra en premier lieu renouveler le cadre chronométrique par la réalisation de grandes séries de datations 14C AMS effectuées sur des matériaux sélectionnés à la fois pour leur caractère intrinsèque (signal isotopique) et leur caractère extrinsèque (contexte archéologique de provenance). Par ailleurs, pour identifier des continuités ou des discontinuités culturelles, il sera nécessaire de s'affranchir des constructions fondées sur l'analyse de la dynamique d'évolution d'une seule variable.

\section{Présentation des données archéologiques et et des datations radiocarbone}

\subsection{Bref historique des recherches}

Entre les années 1952 et 1961, Dumitru Berciu (membre de l'Académie Roumaine) a entrepris de nombreuses recherches de terrain sur la zone des communes actuelles de Baia et de Ceamurlia de Jos (département de Tulcea).

En 1952, 1953, 1954 et 1955 Dumitru Berciu ${ }^{7}$ a réalisé la première étape de la fouille extensive à Ceamurlia de Jos. Ce site a été découvert en 1924, lors de travaux de terrassement sur la voie ferrée Medgidia-Babadag-Tulcea „non loin de Hamangia". On parle du village de Hamangia dont la dénomination turque a été abandonnée en 1929 au bénéfice de Baia. Une „statue-menhir”, quelques tessons, un " casse-tête » en pierre et un reste d'un maxillaire humain récupérés sur place, qui sont assignés à une sépulture datée „plutôt à l'âge du Bronze qu'à celui de la pierre, c'est-à-dire en tout cas à une période très tardive de l'énéolithique du Bas-Danube", ont été publié en 1925 par Vasile Pârvan. Mais ce sont les recherches conduites sur le même site par Dumitru Berciu qui ont permis au moins en partie de révéler les traits de la culture Hamangia. Ce dernier a ainsi fouillé une portion d'un vaste habitat qui se caractérise par la présence de nombreuses fosses (silos) et la présence d'unités d'habitation dont nous ignorons les formes de l'architecture'.

En 1953 et 1954 Dumitru Berciu a réalisé aussi la première étape de la fouille du site de Baia, près du lac Golovița (le site Golovița ou Baia-Golovița) ${ }^{10}$.

Dumitru Berciu va temporairement interrompre ses recherches dans la zone des communes de Baia et Ceamurlia de Jos, au profit des fouilles qu'il conduit sur les sites Hamangia de Cernavoda ${ }^{11}$. Mais Dumitru Berciu poursuivra ses recherches sur les sites de Baia-Golovița, en 1960-1961, et Ceamurlia de Jos, en 1960'12. A l'issue de cette fouille, il publie en $1966^{13}$ son ouvrage de synthèse Cultura Hamangia dans lequel il établit une esquisse chronologique, et l'antériorité de l'établissement de Baia-Golovița sur celui de Ceamurlia de Jos. Ce phasage, établi sur des critères typologiques, n'est à ce jour pas validé par des calages chronologiques absolus. C'est pourquoi nous avons, en fonction du matériel disponible, engagé une campagne de datations radiocarbone.

Les travaux de Dumitru Berciu dans la zone littorale de Hamangia ne se sont pas limités aux habitats de cette culture. En 1954, il réalise un premier sondage sur le tell de Baia ${ }^{14}$, dans l'actuel village (Fig. 2) ${ }^{15}$. C'est en $1961^{16}$ que débute la fouille extensive du tell de Baia, site pour lequel nous ne disposons d'aucune archive de terrain.

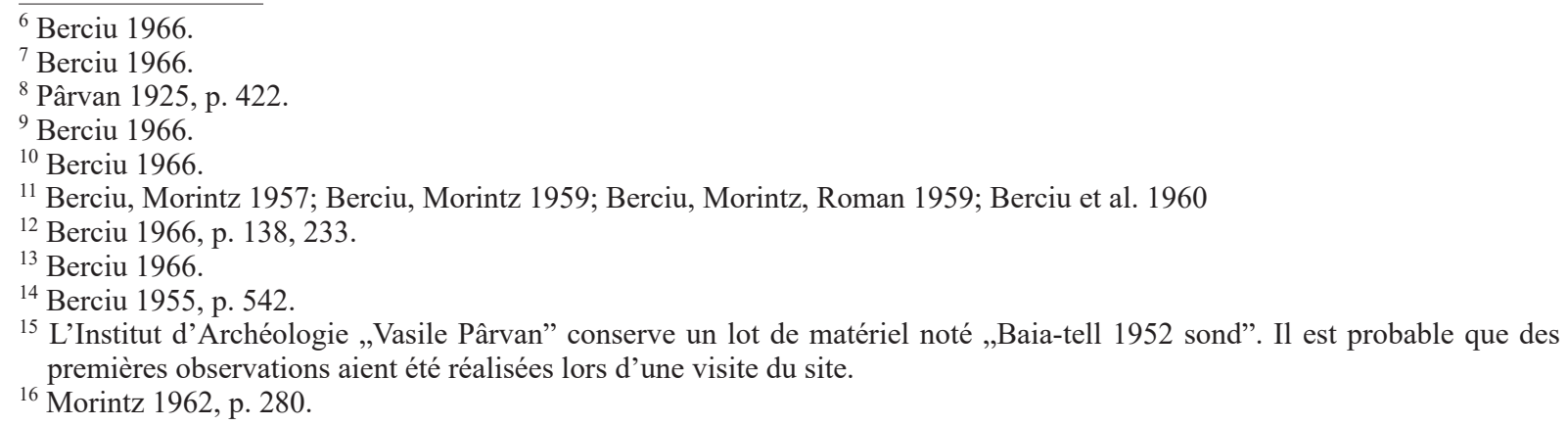




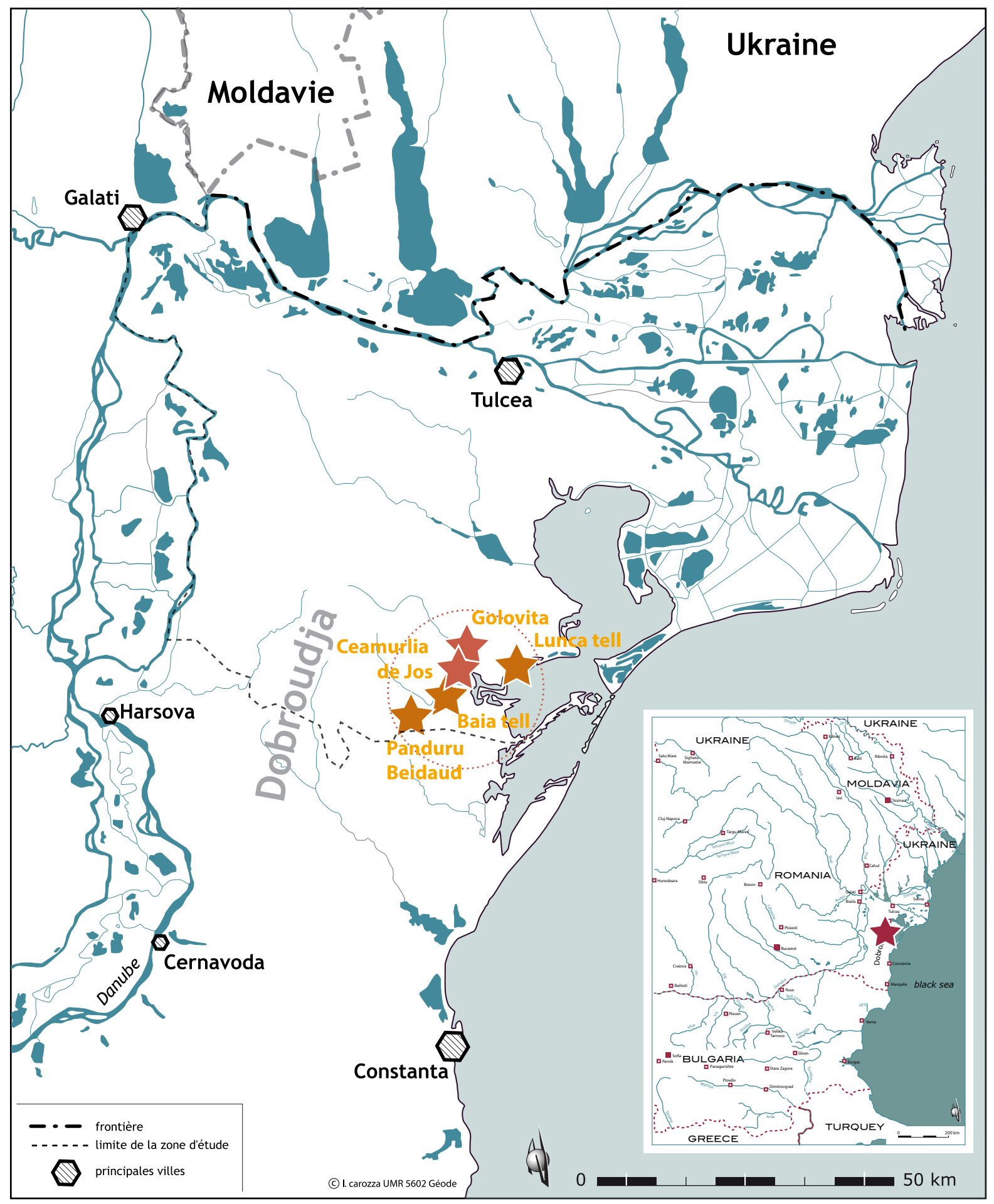

Figure 1. Carte générale de sites néolithiques et chalcolithiques étudiés dans l'arrondissement de Baia dans le cadre de la „mission archéologique Danube" et de l'IRP franco-roumain GOCHE (C) L. Carozza. 
Dans le cadre de la mission „Archéologie du delta du Danube”, nous avons entrepris de reprendre l'ensemble des collections archéologiques disponibles, avant d'envisager toute opportunité de nouvelles recherches de terrain dans la zone littorale (Fig. 1). Outre les sites répertoriés dans la commune de Baia, nous avons repris la documentation relative à l'habitat chalcolithique de Panduru. Ce dernier présente un intérêt majeur, car il est légèrement antérieur à l'établissement du tell de Baia, et présente certains caractères hérités de la culture Hamangia. L'enjeu réside dans l'établissement d'une chronologie absolue de ces établissements de manière à bien caractériser la séquence chrono-culturelle.

\subsection{Les habitats néolithiques Hamangia de Ceamurlia de Jos et de Baia-Golovița}

Dans le cadre de son partenariat avec l'Institut d'Archéologie „Vasile Pârvan” de l'Académie Roumaine, notre équipe a engagé l'étude de deux sites représentatifs de la culture néolithique de Hamangia. Fouillés dans les années 1950-1960 par l'archéologue Dumitru Berciu, les habitats de Ceamurlia de Jos et Baia-Golovița n'avaient pas fait l'objet de publications monographiques. Dans la perspective d'une reprise des fouilles sur ces gisements littoraux (actuelle lagune Razim), nous avons exhumé les archives de fouilles (les carnets de terrain numérisés nous ont été

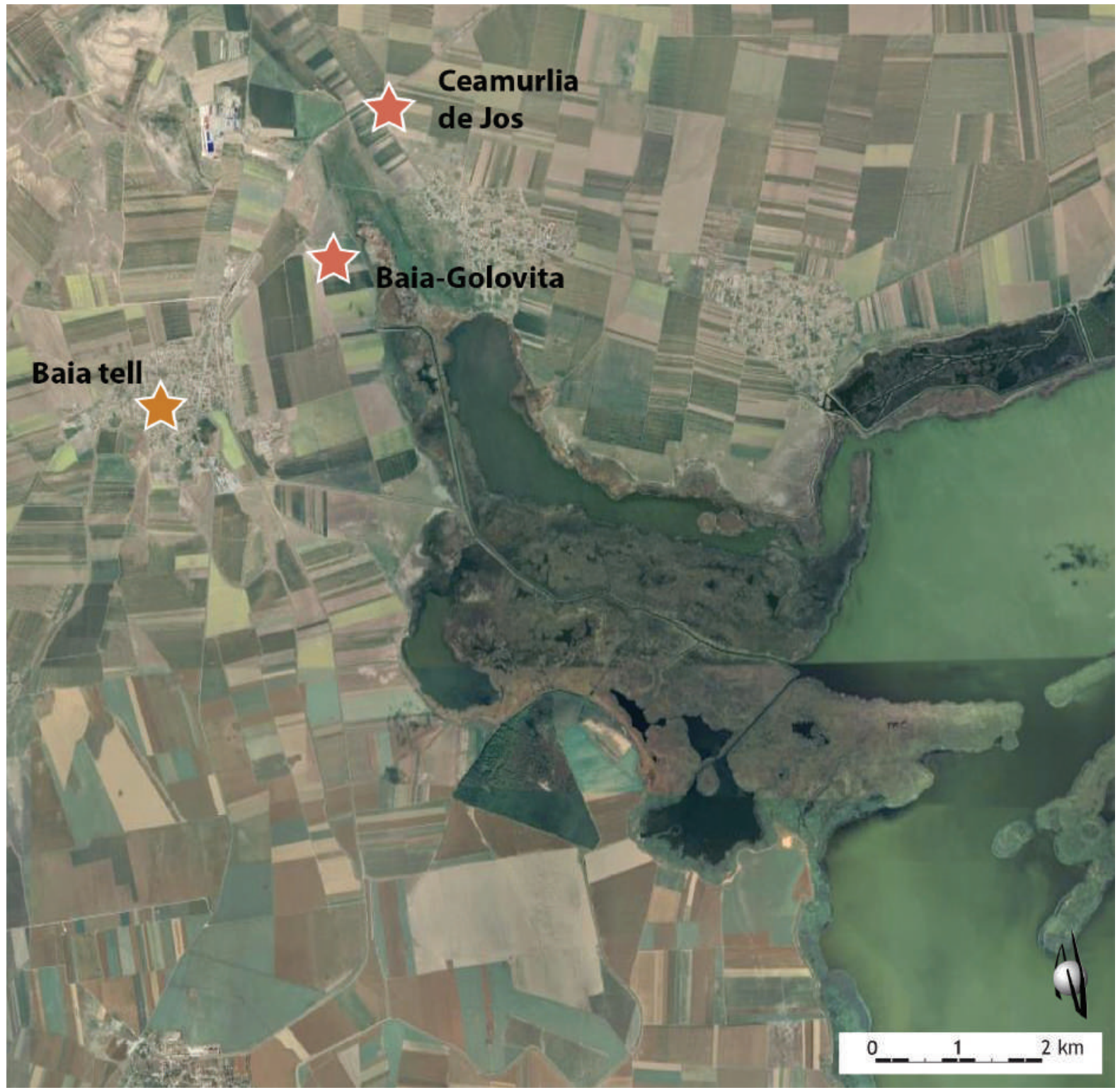

Figure 2. Position des sites fouillés par Dumitru Berciu sur fonds de carte actuel de la bordure de la lagune Razim. 
aimablement fourni par l'Institut d'Archéologie „Vasile Pârvan”" ${ }^{17}$ ) et engagé l'inventaire des collections (plus de 3000 céramiques ont été dessinées inventoriées dans le courant de l'année par notre équipe ${ }^{18}$ ). L'essentiel de nos travaux a porté sur le site de Ceamurlia de Jos, pour lequel nous avons inventorié et dessiné 2990 fragments, contre 542 pour le site de Baia-Golovița. Nous avons constitué une base de données qui consigne des données relatives au type de pâte, au traitement des surfaces et au mode de cuisson. Nous avons également réalisé des observations technologiques, relatives au montage des récipients. Ce projet se poursuivra de manière à achever l'étude des collections anciennes.

\subsubsection{Ceamurlia de Jos}

La fouille du site de Ceamurlia de Jos est très étendue. La zone fouillée est encadrée par des aires d'extractions de matériaux destinés à la construction du chemin de fer. Elle était surmontée d'un vaste tertre tumulaire (Fig. 3). L'habitat néolithique a d'abord été appréhendé par la réalisation de longues tranchées qui ont permis de cerner l'extension des vestiges, puis grâce à une fouille un peu plus extensive qui a révélé l'organisation de l'habitat. La surface A, la plus étendue, a été fouillée sur près de $300 \mathrm{~m}^{2}$, alors que la surface $\mathrm{B}$, contigüe, est nettement plus petite. La surface C ne constitue qu'une petite extension au sein de la tranchée VII. Nous disposons d'un plan général et d'un plan détaillé centré sur la surface A (Fig. 3) qui permettent de repositionner l'ensemble des structures et des faits archéologiques. La fouille de Dumitru Berciu montre que nous sommes en présence d'un habitat ouvert, formé d'unités d'habitations dont la trame est lâche, et de nombreuses structures en creux, pour l'essentiel des fosses-silos.

Le recollement des données est complexe à établir en raison du très grand nombre d'ensembles identifiés et également des discordances observées entre les numéros d'inventaire et les données publiées par Dumitru Berciu ${ }^{19}$. Nous disposons de données planimétriques, individualisées par sections (numérotées de I à VII). Les mobiliers ont été collectés en fonction de la stratigraphie observée par le fouilleur qui a identifié au moins 3 horizons

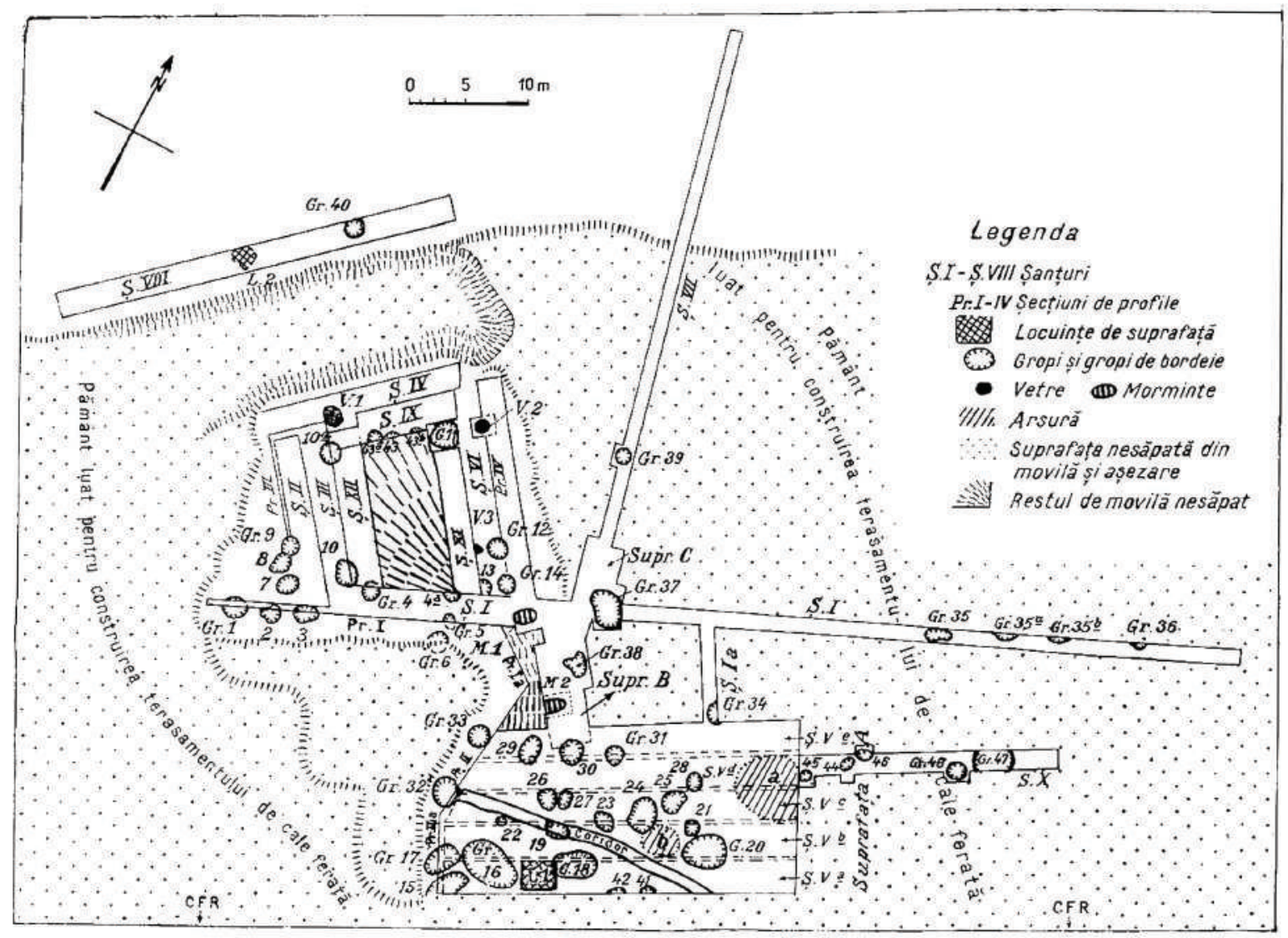

Figure 3. Plan général de la fouille Dumitru Berciu à Ceamurlia de Jos (d'après Berciu 1966).

\footnotetext{
${ }^{17}$ Nous tenons à remercier Mme Roxana Dobrescu d'avoir mis à notre disposition les carnets de terrain numérisés et conservés à l'Institut d'Archéologie.

${ }^{18}$ L'équipe remercie Cristian Ștefan pour son aide dans la mise à disposition des collections archéologiques conservées à l'Institut d'Archéologie.

${ }^{19}$ Berciu 1966.
} 

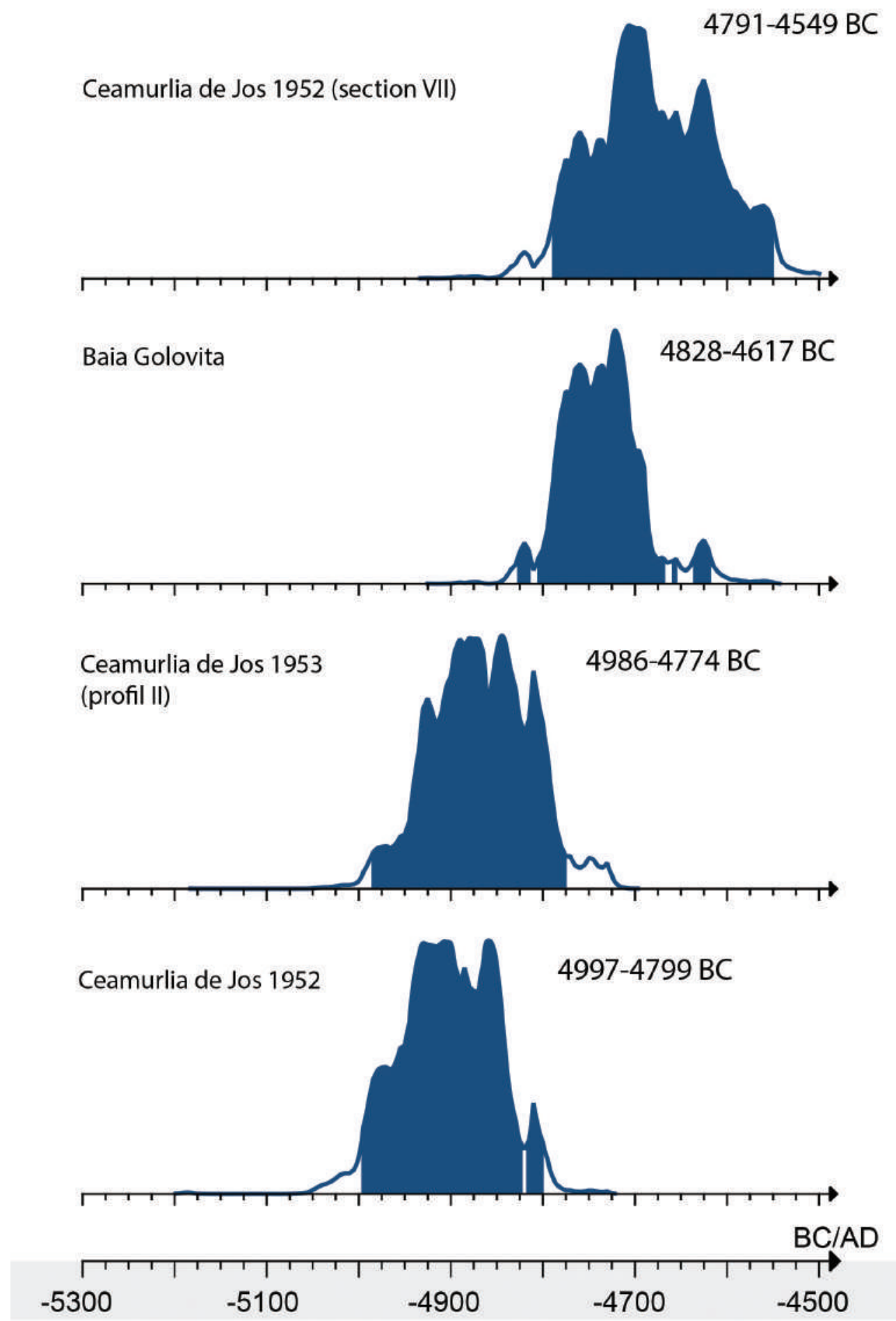

Figure 4. Distribution chronologique des quatre ensembles datés sur les sites de Ceamurlia de Jos et de Baia-Goloviţa. 
successifs (niv. I, II, IIIa et IIIb). Le plus souvent, les lots ne mentionnent que la mention „niveau supérieur” ou „niveau inférieur”. L'exploitation des données nécessitera de réaliser, une fois les inventaires achevés, un schéma stratigraphique simplifié de manière à proposer une sériation des mobiliers issus des fosses et des niveaux archéologiques.

\subsubsection{Baia-Golovița}

Pour ce qui relève de l'habitat de Baia-Golovița, nous n'avons pas encore retrouvé les plans détaillés par structures - s'ils existent - seuls à même de permettre de décrire dans le détail les structures de l'habitat. Les carnets de terrain et la publication de Dumitru Berciu indiquent la présence d'au moins 48 fosses, et de deux unités d'habitations. En outre, un foyer construit a été identifié, ainsi que 2 autres complexes (Cpx 15 et 20). Les données dont nous disposons sur le site de Baia-Golovița sont plus simples, puisqu'elles sont issues soit d'horizons archéologiques fouillés (caseta), soit de fosses (Gr A, D, E, G...), de complexes (Cpx 1, 2a et b, 4a, 5, 6a et 6b, 7b..) et d'unités d'habitation (Loc 1). La fouille des sols ou des horizons archéologiques a été décomposée en plusieurs ensembles, compris entre les altitudes de 0,2 et $0,85 \mathrm{~m}$, dont nous ignorons les liens stratigraphiques.

\subsubsection{Datations radiocarbone des sites Hamangia: remise en contexte}

Avant que de présenter les datations de quatre ensembles archéologiques de la zone de Baia (Fig. 4), il convient de poser le contexte dans lequel ces données ont été établies. Il a été ardu de sélectionner des ensembles représentatifs pour lesquels nous disposions de matériel à dater. En effet, les faunes mises au jour lors des fouilles n'ont pas été retrouvées, et nous avons dû prélever quelques éléments de faune conservés au milieu du mobilier céramique ${ }^{20}$.

Pour le site de Baia-Goloviţa nous avons sélectionné un premier ensemble au sein de la fosse Gr E. Cette dernière a livré un mobilier qui, bien que fragmenté, a livré quelques éléments de formes. On retrouve des écuelles ornées de pointillés obliques, mais également un petit pot tronconique à bord dont on connaît des analogues dans la culture Boian (Fig. 5 n$^{\circ} 5$ ). La date obtenue est la suivante:

Baia, Golovița fouille 1960 Section I, Cas. 2, Gr. E, carré 21-23, Bos taurus (mandibule droite, subadulte/adulte)

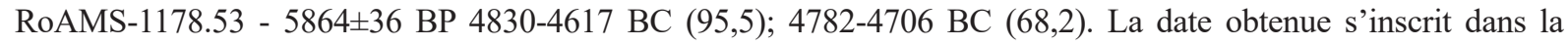
première moitié du $5^{\mathrm{e}}$ millénaire avant notre ère, et très probablement dans le $48^{\mathrm{e}}$ siècle avant notre ère. Bien que cette unique date ne soit pas représentative de l'ensemble de l'occupation du site de Baia-Goloviţa, elle vient contredire l'hypothèse d'une antériorité chronologique totale de l'occupation de ce site sur celui de Ceamurlia de Jos.

En ce qui concerne ce dernier site, nous disposons de davantage de matériel pour réaliser des datations. Le premier ensemble daté est une fosse, mise au jour dans le profil II: Ceamurlia de Jos, fouille 1952 Profil II, Gr 1, Bos taurus (côte) RoAMS-1179.53 - 6013×38 BP (95,5) soit 4997-4822 BC; 4987-4836 (68,2). Cette dernière a livré des céramiques ornées de fins pointillés. Les formes sont classiques de la culture Hamangia, avec des jattes bitronconiques par exemple.

La seconde datation provient également d'une fosse mise au jour dans le même secteur de fouille: Ceamurlia de

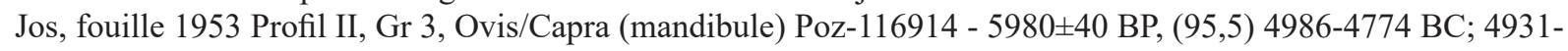
4802 BC $(68,2)$. Les céramiques sont ornées de pointillés imprimés (Fig. 6), et ornent des formes telles que des jattes bi-tronconiques (Fig. $6 \mathrm{n}^{\circ} 1$ ) ou des vases hauts au profil sinueux (Fig. $6 \mathrm{n}^{\circ} 4$ ).

La datation obtenue pour ces deux structures est concordante et place l'occupation de ce secteur de l'habitat au début du $5^{\mathrm{e}}$ millénaire avant notre ère, dans une plage de temps comprise entre le $50^{\mathrm{e}}$ et le début du $48^{\mathrm{e}}$ siècle avant notre ère.

Nous avons également daté un échantillon issu d'un niveau profond (-1,10 m) de la section VII de la fouille. Le résultat obtenu ne témoigne en rien du début de l'occupation du site de Ceamurlia de Jos: Ceamurlia de Jos, fouille 1952 SVII (1,10 m) Poz-116913 - 5820 50 BP (95,5) 4791-4546 BC; 4766-4600 BC (68,2). Bien que les éléments mobiliers mis au jour se rapportent entièrement à la culture Hamangia (Fig. 7), la datation s'inscrit dans une plage de temps longue, comprise entre la seconde moitié du $48^{\mathrm{e}}$ siècle avant notre ère et la première moitié du $46^{\mathrm{e}}$ siècle avant notre ère. La fin de cette période coïncide avec le début de la culture Gumelniţa, tel que nous la percevons en Dobroudja du nord.

\subsubsection{La contemporanéité Hamangia-Boian en Dobroudja du nord}

L'objet de cet article n'est pas de commenter la riche bibliographie relative à la genèse de la culture Hamangia et relative à la synchronisation entre les phases de la culture Hamangia avec les cultures périphériques, et

\footnotetext{
${ }^{20}$ Les échantillons ont été sélectionnés par A. Bălășescu, qui a exclu les restes de suinés et de carnivores en raison des risques liés à la diète de ces animaux.
} 

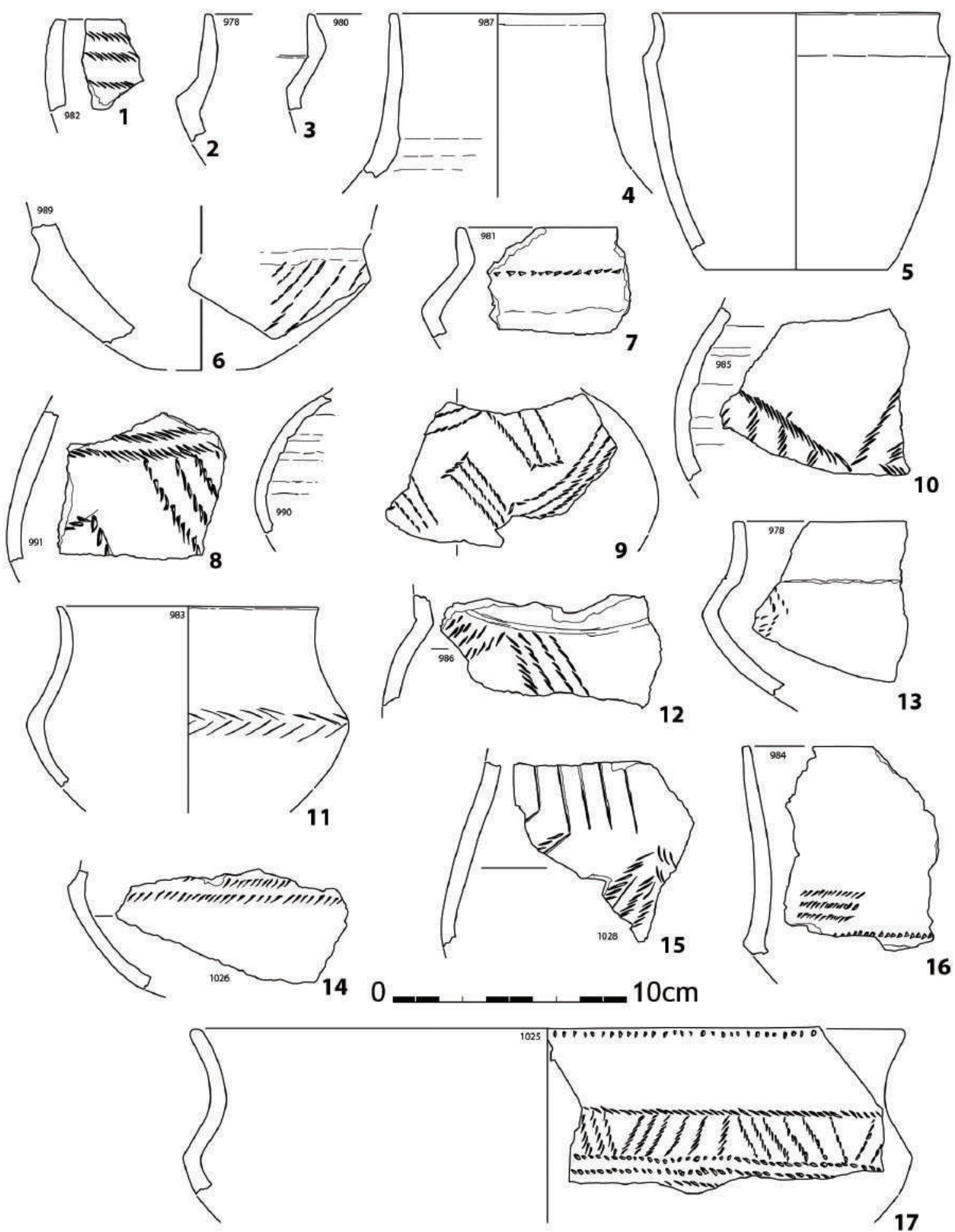

Figure 5. Baia-Golovița, mobilier de la fosse E ( $\mathrm{Gr}$ E); dessin et dessin assisté par ordinateur (DAO) L. Carozza. 


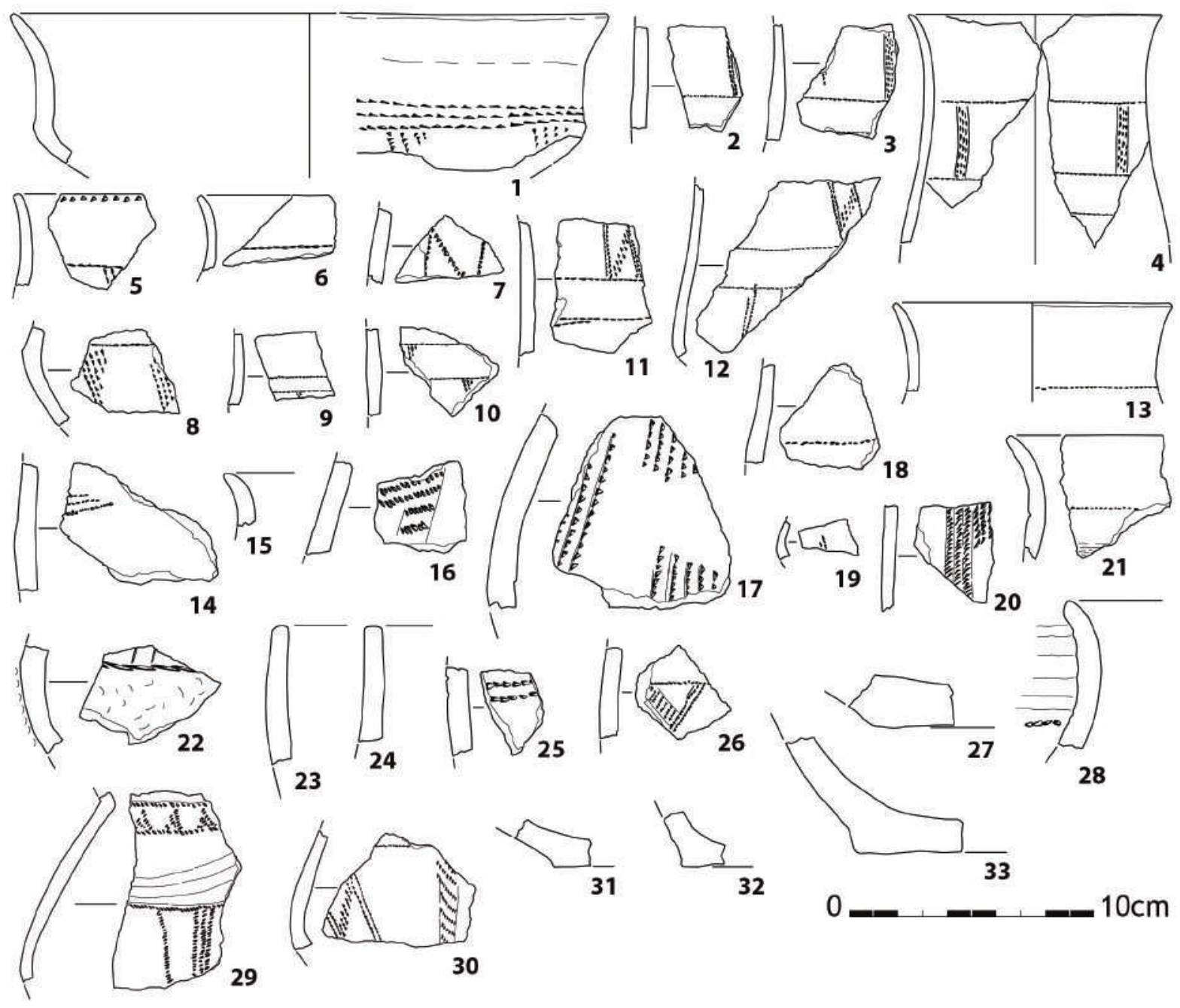

Figure 6. Ceamurlia de Jos, mobilier de la fosse 3 du profil II (Pr II, Gr 3); dessin et DAO L. Carozza.
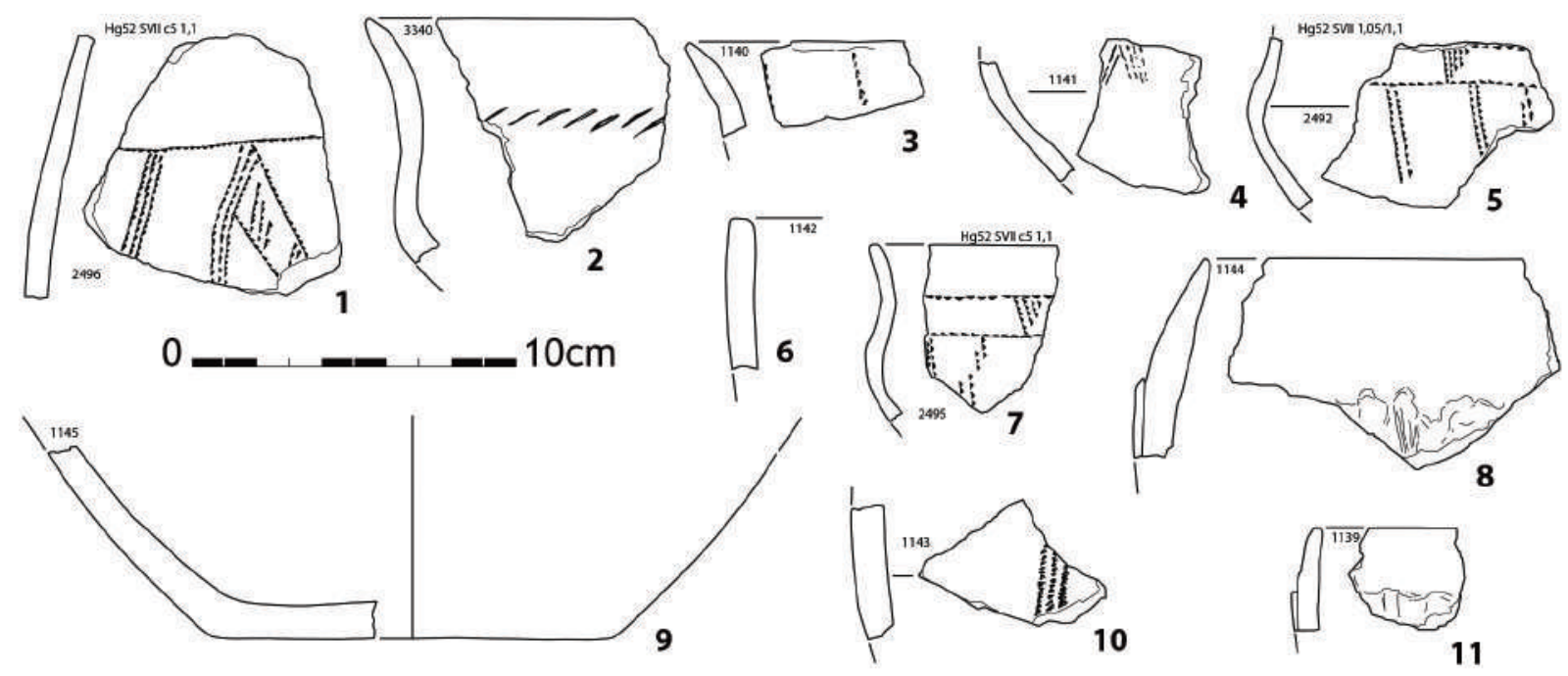

Figure 7. Ceamurlia de Jos, mobilier de la section VII (SVII altitude -1,1 m); dessin et DAO L. Carozza. 
notamment avec la culture Boian ${ }^{21}$, mais plutôt de commenter les données de chronologie absolue relatives à la contemporanéité, en Dobroudja, des deux cultures.

Dans un premier temps, nous avons compilé les datations obtenues pour le complexe culturel Hamangia en Dobroudja (Fig. 8), en intégrant les données obtenues pour le site de Cheia situé dans le département de Constanța ${ }^{22}$ :

- Us 3074 CHE Bos UBA- 6141 \pm 29 BP $(95,5)$ 5206-5003 BC; 5205-5010 BC $(68,2)$

- Us 3094 CHE Cervus UBA- 6064 \pm 26 BP, soit 5005-4937 BC; 5047-4855 BC

- Us 3094 CHE Bos taurus UBA- 6093 \pm 39 BP, soit 5188-4944 BC; 5207-4856 BC

- Us 3118 CHE Bos taurus UBA- 6138 \pm 44 BP, soit 5207-5003 BC; 5214-4961 BC

- Us 3010 CHE Bos UB 6020土43 BP, soit 4977-4846 BC ; 5020-4797 BC

La compilation des datations montre une succession évidente entre les occupations du site de Cheia et les habitats de la zone de Baia. Ces données manifestent que le début de l'occupation de l'habitat de Cheia se situerait au début du $53^{\mathrm{e}}$ et la fin du $51^{\mathrm{e}}$ siècle avant notre ère (Us 3118 et 3074). Une seconde étape de l'occupation du site se développerait au début du $5^{\mathrm{e}}$ millénaire avant notre ère, entre le $50^{\mathrm{e}}$ et le début $48^{\mathrm{e}}$ siècle avant notre ère. Cette étape de l'occupation serait contemporaine de la première étape de l'occupation de l'habitat de Ceamurlia de Jos (fosses du profil Pr II), soit entre 5000 et 4800 BC. Une dernière étape de l'occupation de la zone de Baia se développerait durant la première moitié du $5^{\mathrm{e}}$ millénaire avant notre ère, entre 4800 et $4600 \mathrm{BC}$.

Bien que le nombre de dates soit encore très limité, nous pouvons estimer que le complexe Hamangia en Dobroudja se développerait entre les $53^{e}$ siècles avant notre ère et le $47^{\mathrm{e}}$ siècle avant notre ère, soit environ sur une durée de 6 siècles. Ce modèle ne présage pas de l'existence d'une phase ancienne de la culture Hamangia ou d'un Néolithique ancien non encore déterminé, qui serait antérieur au $53^{\mathrm{e}}$ siècle avant notre ère.

Ces nouvelles datations nous permettent plus particulièrement d'estimer la chronologie de la fin de la séquence Hamangia et sa contemporanéité avec les autres complexes culturels. Pour ce faire, nous avons pris en compte les datations réalisées sur le site d'Isaccea, fouillé par Cristian Micu dans la zone du Danube ${ }^{23}$ et sur le site de chalcolithique de Niculițel ${ }^{24}$. Le site d'Isaccea se rattache au complexe Boian, bien que des éléments de type Hamangia y aient été mis en évidence. Toutefois, les ensembles datés et utilisés ici se rapportent uniquement au complexe Boian. Quant au site de Niculițel, les ensembles fouillés sur ce site sont intéressants, car ils se rapportent à la culture Gumelnița, mais comportent des traits résiduels de la culture Boian, tels des décors excisés.

La compilation de ces dates (Fig. 9), montre clairement qu'il existe une contemporanéité entre les complexes culturels Boian d'Isaccea (fosse 36 et unité domestique 2) et les occupations Hamangia de Ceamurlia de Jos et Baia-Golovița. La plage de temps commune est comprise entre le $49^{\mathrm{e}}$ et le $48^{\mathrm{e}}$ siècle avant notre ère. On peut estimer que la fin des séquences Hamangia et Boian pourrait être synchrone, aux alentours de 4650-4600 BC, comme l'indiquent les dates obtenues sur les niveaux d'abandon de l'unité domestique 2 de Isaccea ou la section VII de Ceamurlia de Jos. Le début de la séquence Gumelnița s'amorcerait vers 4600 BC, non pas en rupture totale, mais en transition avec les groupes de la culture Boian qui peuplaient les zones riveraines du Danube. Ce modèle se fonde sur l'existence d'une étape de transition entre les complexes culturels du début du Chalcolithique et l'émergence du méga-complexe Kodjadermen-Gumelnița-Karanovo VI, plutôt que sur celle d'une rupture majeure entre ces ensembles culturels. Cette hypothèse devra être confortée par de nouvelles données dans la zone riveraine de la mer Noire. C'est pourquoi nous avons repris les données des habitats de Panduru attribués à la phase ancienne du complexe culturel Gumelnița ${ }^{25}$ et du tell de Baia - „Boruz” qui a livré une séquence stratigraphique exploitable pour la zone riveraine des zones lagunaires.

\subsection{Le tell de Baia „Boruz”}

Le tell chalcolithique de Baia a fait l'objet d'une fouille conduite par Dumitru Berciu, à la suite d'une série de sondages menés $1954^{26}$. Il semble avoir réalisé la fouille de cet établissement en $1961^{27}$, au point où il nous est impossible de localiser les zones fouillées avec précision (Fig. 10). Nous avons reporté l'emplacement du tell sur

\footnotetext{
${ }^{21}$ Berciu 1966; Dumitrescu 1970; Dumitrescu 1971; Dumitrescu 1974; Dumitrescu, Bolomey, Mogoșanu 1983; Hasotti 1997.

22 Balasse et al. 2014; Torneo et al. 2013; Voinea, Neagu 2006; 2008; Voinea, Dobrinescu 2003; Voinea et al. 2007; Voinea, Neagu, Radu 2009.

${ }^{23}$ Micu 2006.

${ }^{24}$ Micu et al. 2009, p. 14; Ailincai, Topoleanu, Mihail 2016.

${ }^{25}$ Lungu, Micu 2003.

${ }^{26}$ Berciu 1955, p. 542.

${ }^{27}$ Morintz 1962, p. 280.
} 
le cadastre sur la base de témoignages.

Il ne subsiste à ce jour aucune archive relative à cette fouille. Nous avons toutefois entrepris des recherches dans les archives de l'Institut d'Archéologie „Vasile Pârvan”, mais également dans les archives départementales de Constanţa qui conservent la correspondance de Dumitru Berciu.

En l'absence de plans et de sections, nous avons réalisé un inventaire complet des 110 ensembles individualisés par le fouilleur sur le terrain. Les sacs de mobilier portent en effet différentes informations. La mention «Cas» (caseta en roumain) nous renvoie vers l'entité spatiale fouillée (carré ou tranchée). Chaque lot de mobilier porte également une mention stratigraphique indiquant l'altitude supérieure et inférieure de la couche fouillée. Parfois, d'autres indications ont été rapportées sur les sacs. Il est fait mention de maisons notées « Loc pour locuinta » ou de fosses notées „Gr pour groapă”.

Notre premier travail a t-il ainsi été conduit à l'aveugle. Nous avons inventorié et dessiné l'ensemble des mobiliers conservés. On notera qu'un tri typologique sélectif a été opéré, car seuls les éléments de formes ou de décors ont été conservés. Nous disposons, à l'issue de ce travail, d'un corpus composé de 2114 individus.

Ces mobiliers sont inégalement répartis au sein de 16 entités spatiales „,cas.”. On observe cependant que des lots de mobiliers ont été réunis au sein d'entités multiples contigües, dont la numérotation se succède (cas 3-45 ; cas 4-6; cas 6-7...). Ce qui semble indiquer que les entités de fouille ont été nommées de manière ordonnée. Les regroupements paraissent rassembler des entités stratigraphiques cohérentes (couches d'habitat, niveau de destruction...), présentant une continuité spatiale évidente. En l'absence de plans, nous nous sommes appuyés sur ces recoupements pour proposer une présentation ordonnée des différents ensembles (Fig. 11a). Sur cette première représentation, nous avons reporté les entités stratigraphiques telles que notées par le fouilleur, c'est-àdire avec des mesures effectuées depuis la surface du sol. Nous avons de la sorte extrait la courbe de l'altitude de base atteinte dans chacune des entités spatiales, de manière à proposer une restitution de la paléo-topographie du tell (Fig. 11b). En inversant l'image, nous obtenons une représentation théorique de la courbure de surface du tell. Nous disposons d'autres informations qui indiquent la présence d'un établissement antique au sommet du tell (Fig. 11b). L'inventaire des mobiliers antiques, et en corollaire l'absence de céramiques attribuables au Chalcolithique, semble indiquer que cette occupation était limitée dans l'espace (cas 4 à 8), et limitée en profondeur aux 60 premiers centimètres. De fait cette occupation a très peu affecté les niveaux de la Préhistoire récente. Parmi les informations recueillies, nous avons isolé un lot de mobilier recueilli en 1952, sur lequel il est indiqué „,sondaj cariera". Cette mention semble corroborer les informations selon lesquelles le tell aurait pu servir de carrière pour extraire des matériaux.

Suite à la première intervention de Dumitru Berciu sur le tell - au moment où il fouillait Ceamurlia de Jos un second lot de mobilier est consigné „1954 sondaj tell”. Toute porte à croire que le fouilleur a fait réaliser à l'occasion de la dernière campagne de terrain à Ceamurlia de Jos une fouille plus extensive sur le tell de Baia. Nous ignorons tout de la localisation de ces sondages, ainsi que de leur portée stratigraphique.

Nous avons proposé une représentation théorique de la distribution stratigraphique de chacun des ensembles mobiliers, représentation qui tient compte de la restitution de la paléo-topographie (Fig. 11b). La puissance stratigraphique maximale du tell approche $3 \mathrm{~m}$ dans sa partie la plus développée. Ce tell est comparable, de par sa puissance aux tells de Taraschina et de Luncavița.

Pour donner une idée de la distribution des mobiliers céramiques, nous avons tenté de représenter la distribution spatiale et stratigraphique des éléments de formes dessinés (Fig. 12). Nous avons découpé la stratigraphie en 3 grands ensembles (ancien, moyen et récent) au vu de la distribution des mobiliers. Il apparaît clairement que la phase moyenne est la mieux représentée, au détriment de l'étape ancienne pour laquelle les effectifs demeurent très faibles, alors que la phase récente est très affectée par les aménagements antiques.

La distribution spatiale est assez inégale. On observe une forte densité de restes dans la portion comprise entre les ensembles 8 à 14. De fait, ces ensembles sont, statistiquement, les plus à même de permettre une approche diachronique de l'évolution de la culture matérielle. Les données typologiques dont nous disposons montrent que l'ensemble de la séquence chrono-culturelle se rapporte au Chalcolithique, et plus spécifiquement à la phase ancienne et moyenne de la culture de Gumelnița. L'importance des décors incisés, sur des formes au profil segmenté (épaulement et carènes), vient corroborer cette datation. Nous avons, à titre d'exemple, tenté d'analyser la distribution des céramiques peintes au graphite (Fig. 13). La figure montre que les céramiques peintes de motifs gris sont très rares à la base de la séquence, alors que les occurrences les plus nombreuses se rapportent pour l'essentiel à la phase moyenne, notamment dans l'ensemble 11. Ces quelques exemples montrent qu'il est envisageable, en dehors de l'aspect strictement documentaire (Fig. 14), de tenter une approche diachronique des 

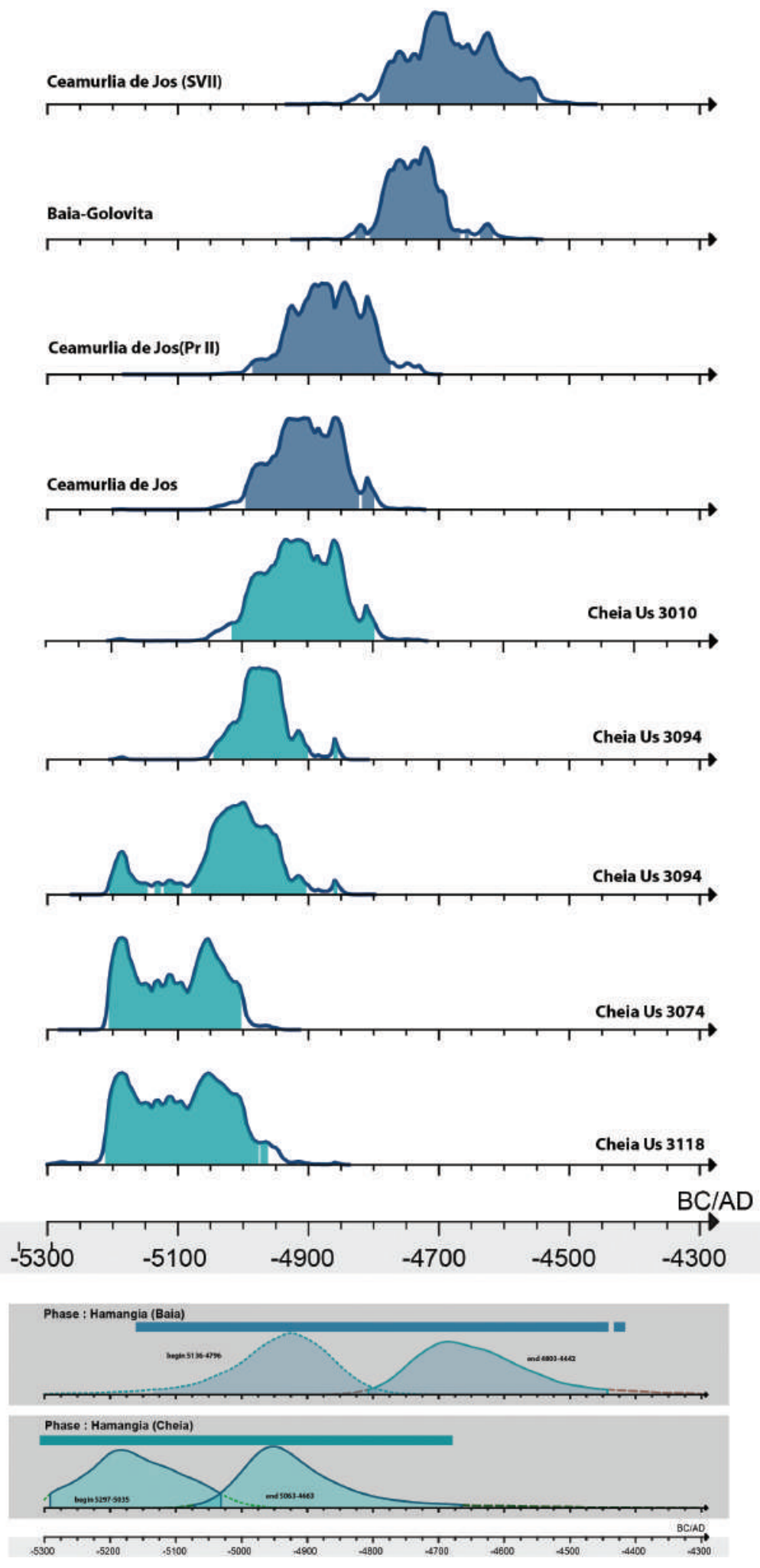

Figure 8. La séquence chronologique Hamangia vue au travers des datations des sites de Ceamurlia de Jos, Baia-Golovița et Cheia. 


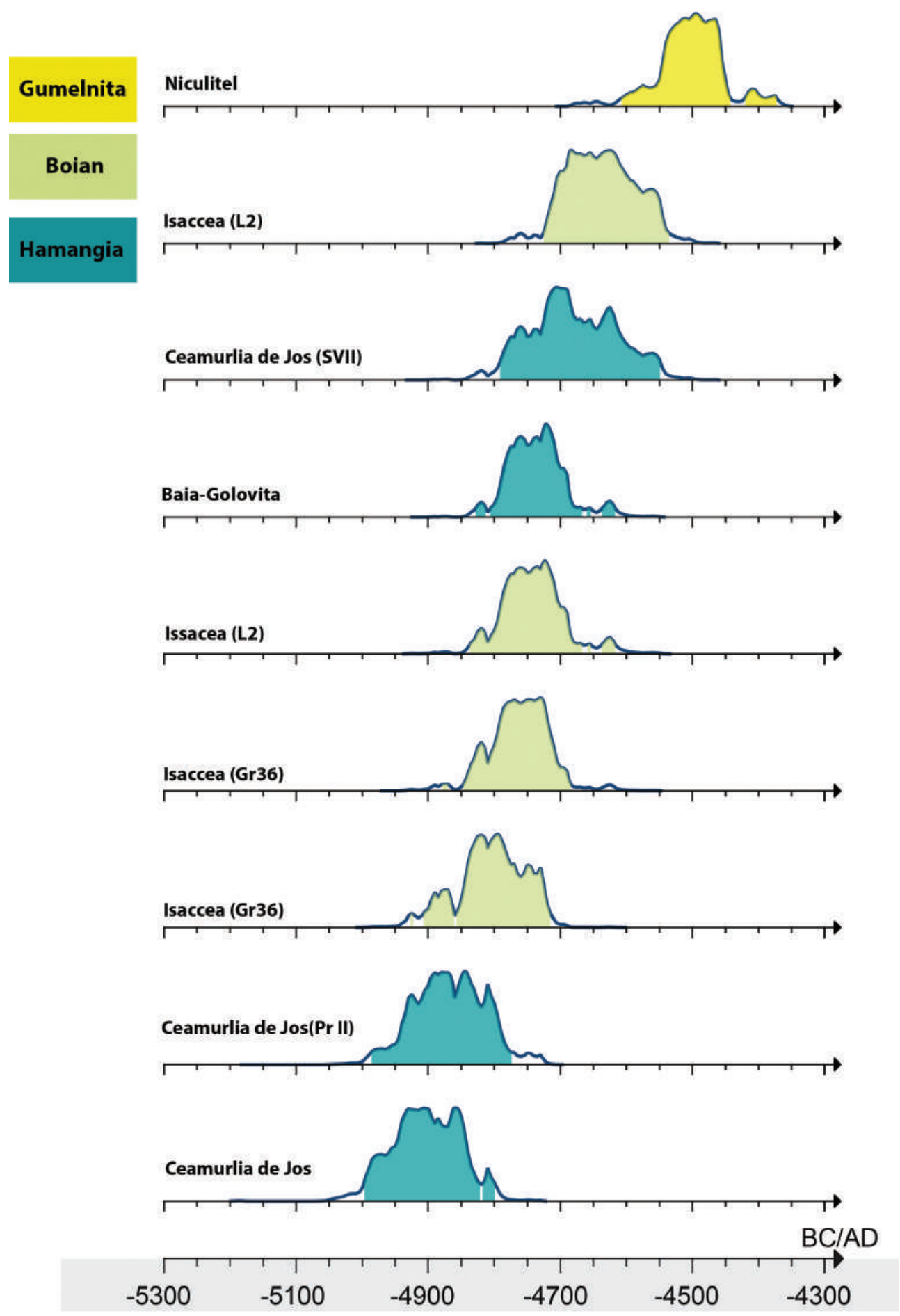

Figure 9. Séquence chronoculturelle Hamangia/Boian en Dobroudja du nord d'après les datations radiocarbone de quelques ensembles représentatifs. 


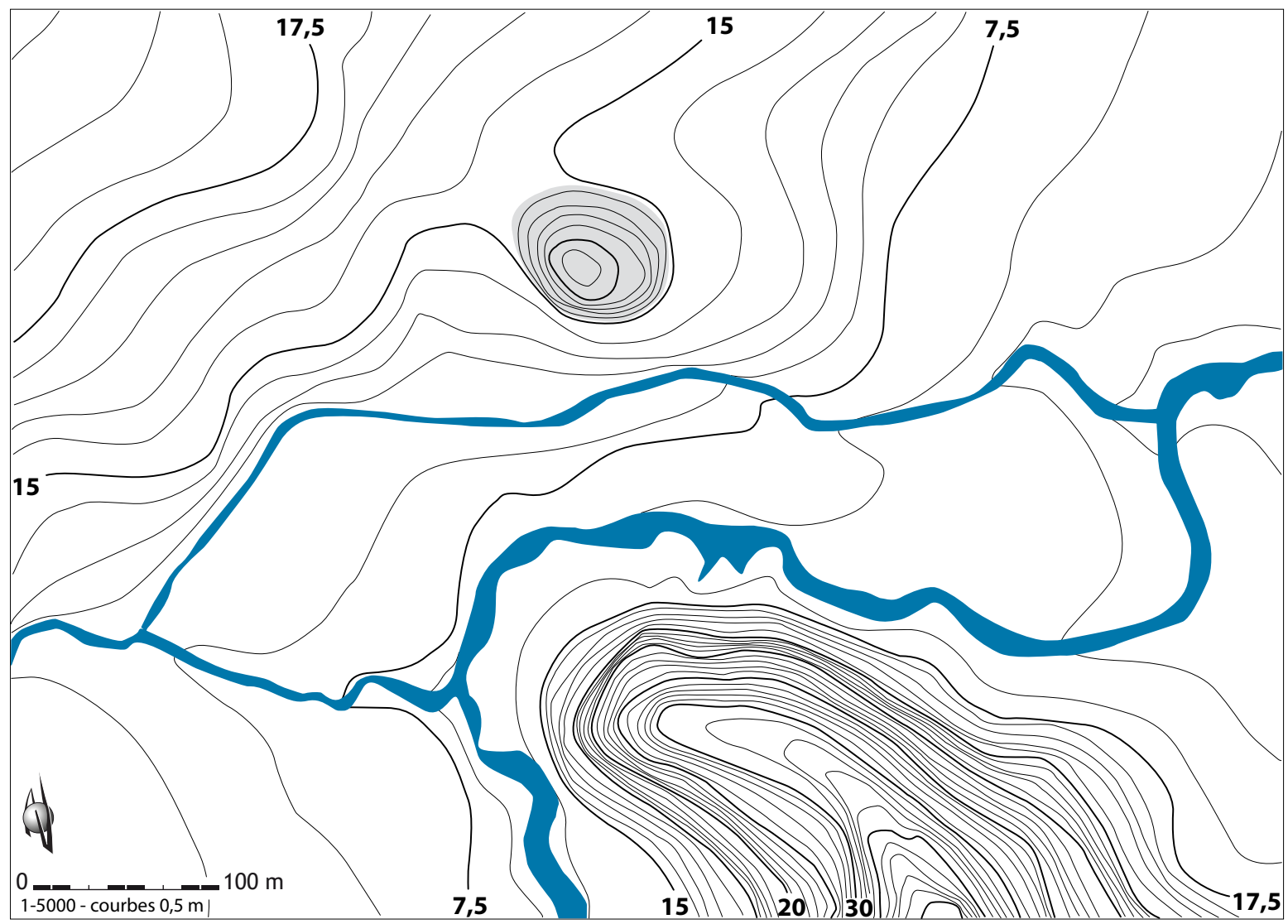

Figure 10. Emplacement supposé du tell Baia „Boruz” sur la carte topographique au 1-5000 de 1970; DAO L. Carozza.

ensembles mobiliers du tell de Baia. Pour valider notre démarche, nous allons réaliser des datations radiocarbone en différents ensembles de la séquence, de manière à procéder à une approche quantitative globale, en 3 phases distinctes.

\subsection{Perspectives}

Le travail de relecture des collections anciennes de la zone des rivages lagunaires de la mer Noire constitue la phase liminaire de l'ouverture d'une nouvelle fenêtre de recherche. Depuis 1966, date de la publication de la monographie de Dumitru Berciu relative à la culture de Hamangia, la question du Néolithique de Dobroudja n'avait pas fait l'objet d'une relecture attentive. Nous ne disposions, par exemple, d'aucun phasage fiable, fondé sur une série de datations radiocarbone.

Parallèlement, la question de la genèse de la culture Hamangia n'avait pas fait l'objet de relecture depuis les années 1970. Les sites éponymes de la culture Hamangia de Baia-Golovița et de Ceamurlia de Jos n'avaient jusqu'à aujourd'hui pas fait l'objet d'une publication exhaustive; seuls environ $20 \%$ des mobiliers avaient été publiés. Si le mobilier céramique a en partie été conservé, les autres vestiges ne l'ont pas été. Nous souhaiterions pouvoir reprendre l'étude des industries lithiques taillées et polies, mais ces dernières ont en grande partie disparue. Il en est de même pour les faunes.

De fait, les questions relatives à l'économie de ces communautés néolithiques et à leur relation avec leur environnement (exploitation des ressources des milieux lagunaires et marins par exemple) nécessiteront, pour trouver des éléments de réponse, de revenir sur le terrain de manière à échantillonner des ensembles archéologiques. En 2020, nous souhaitons engager un programme de prospection géophysique dans la zone des rivages lagunaires du lac Razim dans la perspective de reprendre des recherches de terrain dans les années à venir. 
Distribution alimétrique des lots étudiés tels qu'enregistrés
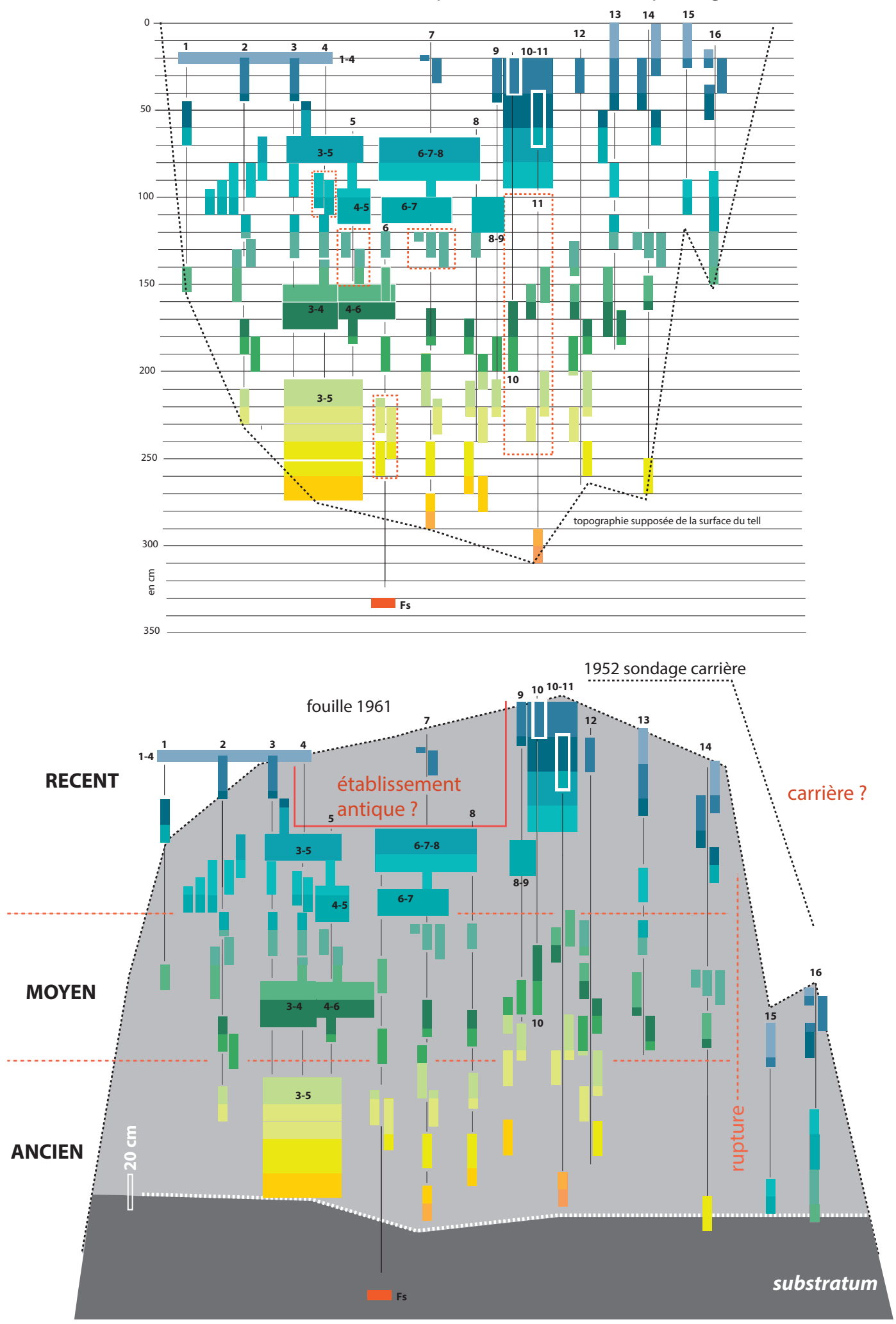

Proposition de restitution de la stratigraphie

Figure 11. Distribution stratigraphique des ensembles céramiques chalcolithiques individualisés par Dumitru Berciu lors de la fouille de 1961: (a) distribution selon les côtes altimétriques notées par le fouilleur; (b) distribution corrigée en fonction de la paléo-topographie supposée du tell; DAO L. Carozza. 

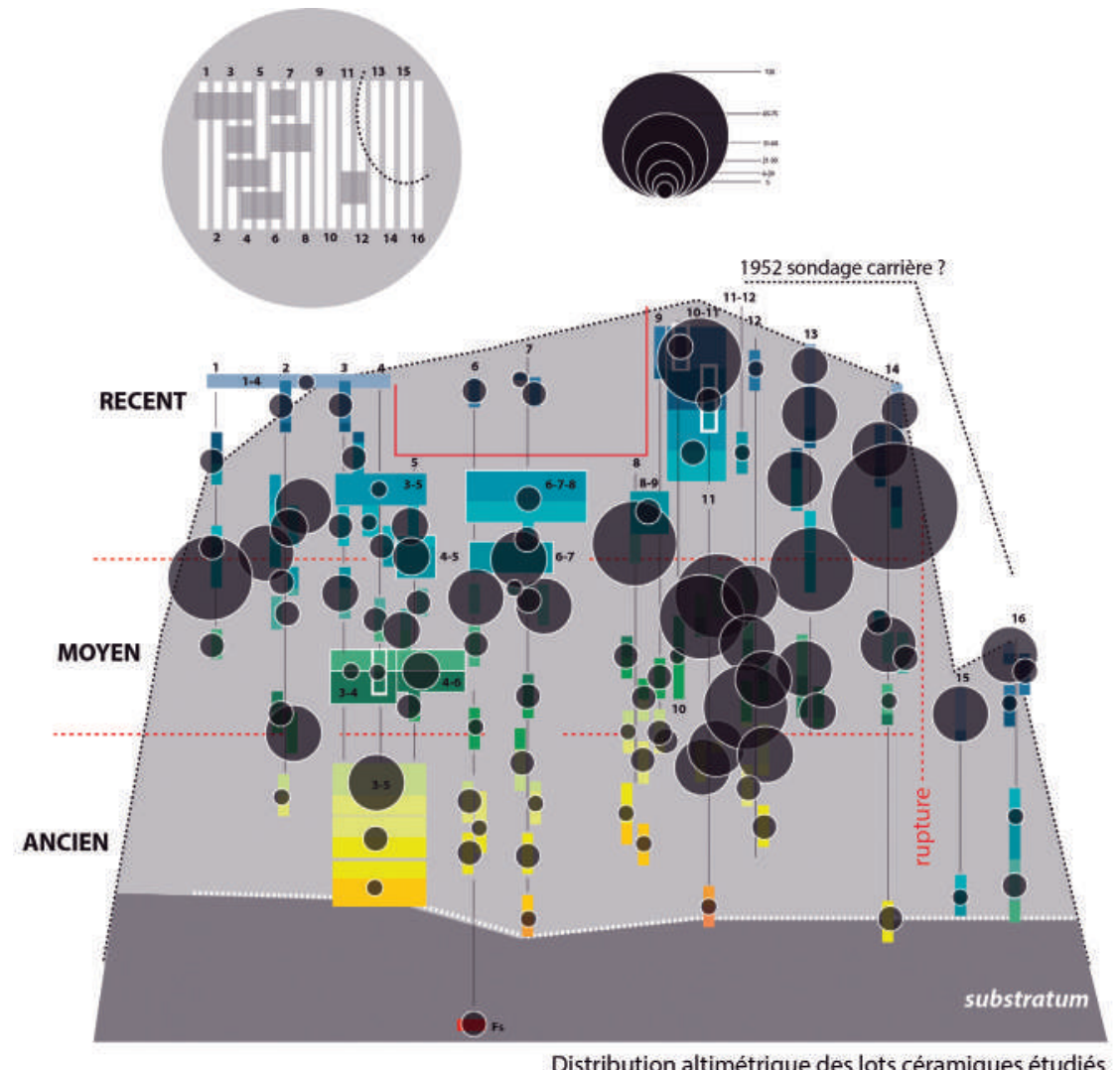

Figure 12. Distribution du nombre de formes caractéristiques collectées par Dumitru Berciu lors de la fouille de 1961 sur le tell de Baia „Boruz”; DAO L. Carozza.

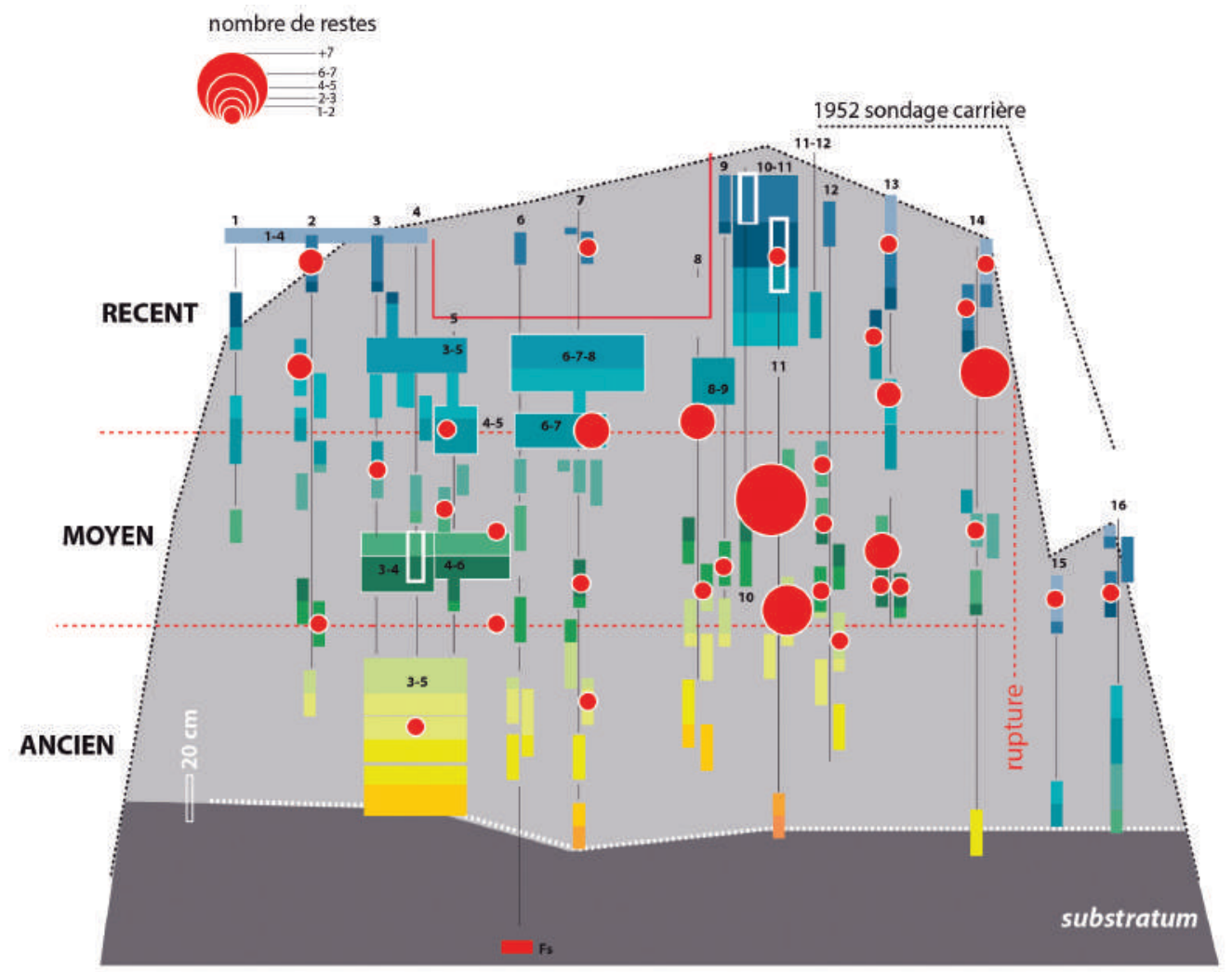

distribution des céramiques peintes au graphite

Figure 13. Distribution du nombre de céramiques peintes au graphite collectées par Dumitru Berciu lors de la fouille de 1961 sur le tell de Baia „Boruz”; DAO L. Carozza. 


\section{Remerciements}

Cette étude s'inscrit dans un programme de Institut d'archéologie „Vasile Pârvan“ „Structures économiques, technologiques et culturelles dans les communautés néolithiques de la Dobrogea du nord - relecture des collections de Berciu et l'intégration de nouvelles données du terrain” (A. Bălășescu). Ce projet a bénéficié de financements de l'IRP GOCHE „Géoarchéologie du bas Danube et son Delta” et de la mission „Archéologie Delta du Danube”du Ministère Français des Affaires Etrangères et du Développement International. Deux datations radiocarbones (RoAMS) ont été réalisé dans le cadre du projet CCDI-UEFISCDI PN-III-P1-1.2-PCCDI-2017-0686 (PatCult\#RO).
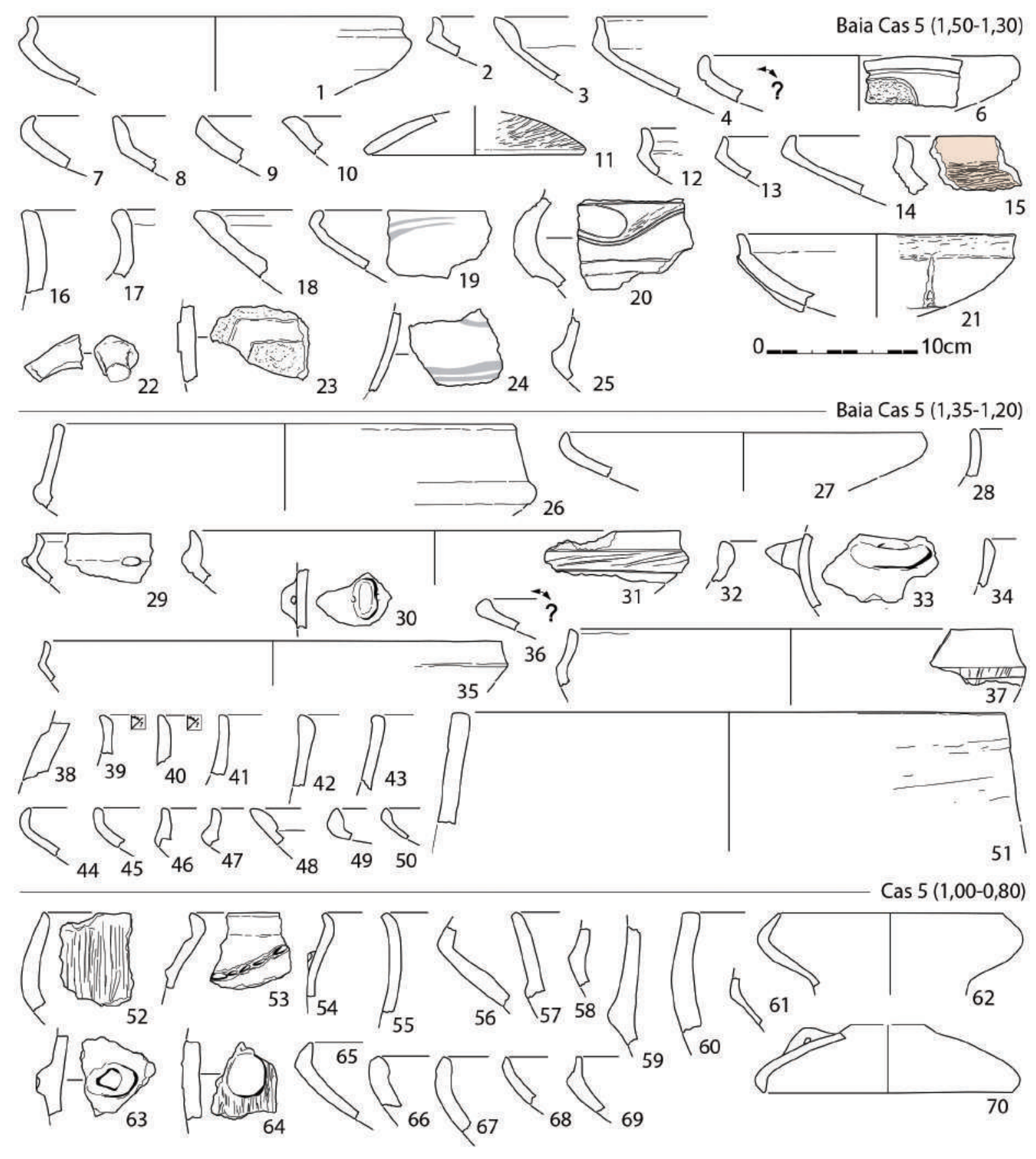

Figure 14. Exemple de présentation stratigraphique des mobiliers céramiques collectés par Dumitru Berciu lors de la fouille de 1961 sur le tell de Baia „Boruz” - dans le carré 5; dessin S. Ailincai / DAO L. Carozza. 


\section{BIBLIOGRAPHIE}

Ailincăi, Topoleanu, Mihail 2016

Balasse et al. 2014

Bălășescu 2008

Berciu 1955

Berciu 1966

Berciu, Morintz 1957

Berciu, Morintz 1959

Berciu, Morintz, Roman 1959

Berciu et al. 1960

Burens et al. 2010

Carozza, Bem, Micu 2011

Carozza et al. 2014

Dumitrescu 1970

Dumitrescu 1971

Dumitrescu 1974

Dumitrescu, Bolomey, Mogoșanu 1983

Furestier et al. 2017

Guilaine 2007

Lanos, Dufresne 2019
Ailincăi, S. C., Topoleanu, F., Mihail F., Așezarea din perioada timpurie a epocii fierului de la Niculițel - Cornet, jud. Tulcea. Cercetările arheologice din anul 1988, Peuce S.N., XIV, 2016, 233-292.

Balasse, M., Tornero, C., Bréhard, S., Ughetto-Monfrin, J., Voinea, V., Bălășescu, A., Cattle and sheep herding at Cheia, Romania, at the turn of the fifth millennium cal BC. A view from stable isotope analysis, Proceedings of the British Academy, 198, 2014, 115-412.

Bălășescu, A., Considerații cu privire la exploatarea mamiferelor în așezarea Hamangia III de la Cheia, Pontica, 41, 2008, 49-56.

Berciu, D., Cercetări în teritoriul rural al Histriei. 1. Așezarea neolitică de la BaiaHamangia, SCIV, VI, 3-4, 1955, 541-542.

Berciu, D., Cultura Hamangia, Vol. I, Editura Academiei Republicii Socialiste România: București, 1966.

Berciu, D., Morintz, S., Şantierul arheologic Cernavodă (reg. Constanța, r. Medgidia), Materiale și Cercetări Arheologice, III, 1957, 80-92.

Berciu, D., Morintz, S., Săpăturile de la Cernavodă (r. Medgidia, reg. Constanța), Materiale și Cercetări Arheologice, V, 1959, 99-114

Berciu, D., Morintz, S., Roman, P., Săpăturile de la Cernavodă (r. Medgidia, reg. Constanța), Materiale și Cercetări Arheologice, VI, 1959, 95-105.

Berciu, D., Morintz, S., Ionescu, M., Roman, P., Şantierul arheologic Cernavodă, Materiale și Cercetări Arheologice, VII, 1960, 49-55.

Burens, A., Ailincăi, S., Micu, C., Carozza, L., Lazurcă, E., Premières observations sur les techniques de façonnage et de finition de la céramique chalcolithique Gumelnița A2 du site de Carcaliu (Dobroudja, Roumanie), Studii de Preistorie, 7, 2010, 95-123.

Carozza, L., Bem, C., Micu, C. (eds.) Société et environnement dans la zone du Bas Danube durant le 5ème millénnaire avant notre ère, Editura Universității „Alexandru Ioan Cuza” Iași, Iași, 2011.

Carozza, L., Micu, C., Ailincăi, S., Mihail, F., Carozza, J.-M., Burens, A., Cercetări în așezarea-tell de la Lunca (com. Ceamurlia de Jos, jud. Tulcea, în Ștefan, C.-E., Florea, M., Ailincăi, S.-C., Micu, C. (eds.), Studii privind preistoria sud-estului Europei. Volum dedicat memoriei lui Mihai Simon, Biblioteca Istro-Pontica, Seria Arheologie 10, Muzeul Brăilei, Editura Istros, Brăila, 2014, 214-233.

Dumitrescu, V1., Cu privire la cea mai veche cultură neolitică din România, $S C I V$, 21, 2, 1970, 187-199.

Dumitrescu, V1., În legătură cu vechimea culturii Hamangia, Peuce, II, 1971, 3-9.

Dumitrescu, Vl., Cronologia absolută a neoliticului românesc în lumina datelor C14, Apulum, 12, 1974, 23-39.

Dumitrescu, Vl., Bolomey, Al., Mogoșanu, Fl., Esquisse d'une préhistoire de la Roumanie jusqu'à la fin de l'âge du bronze, Editura Științifică și Enciclopedică, București, 1983.

Furestier, R., Mihail, F., Manolakakis, L., Philibert, S., Carozza, L., Micu, C., Les industries lithiques énéolithiques de la Dobroudja du Nord, Materiale și Cercetări Arheologice, S.N. XIII, 2017, 213-226.

Guilaine, J. (dir.), Le Chalcolithique et la construction des inégalités, Tome 1, Le continent européen, Éd. Errance, Paris, 2007.

Lanos, P., Dufresne, P., Chronomodel, version 2.0: software for Chronological Modeling of Archaeological Data Bayesian Statitistic, https://chronomodel.com, visitée decembre 2019. 
Lungu, Micu 2003

Micu 2006

Micu et al. 2009

Mihail, Ștefan 2014

Morintz 1962

Pârvan 1925

Radu 2008

Reingruber 2015

Tornero et al. 2013

Voinea 2010a

Voinea 2010b

Voinea, Dobrinescu 2002-

2003

Voinea, Neagu 2006

Voinea, Neagu 2008

Voinea et al. 2007

Voinea, Neagu, Radu 2009

Voinea, Grigoruță, Cărpuș 2014
Lungu, V., Micu, C., Cercetările arheologice de salvare de la Panduru, jud. Tulcea, Peuce S.N., I, 2003, 11-44.

Micu, C., Neo-eneoliticul în nordul Dobrogei în lumina cercetărilor de la Isaccea şi Luncavița. Volumul I. Neoliticul în nordul Dobrogei, Editura Harvia: Tulcea, 2006.

Micu, C., Mihail, F., Carozza, L., Florea, M., Câteva observații asupra unor situri eneolitice din zona de nord a Dobrogei, Peuce S.N., VII, 2009, 9-48.

Mihail, F., Ștefan, C.-E., Obiecte din piatra si materii dure animale descoperite in tell-ul de la Baia, jud. Tulcea, în Ștefan, C.-E., Florea, M., Ailincăi, S.-C., Micu, C. (eds.), Studii privind preistoria sud-estului Europei. Volum dedicat memoriei lui Mihai Simon, Biblioteca Istro-Pontica. Seria Arheologie 10, Muzeul Brăilei, Editura Istros, Brăila, 2014.

Morintz, S., Tipuri de așezări si sisteme de fortificație și de împrejmuire în cultura Gumelnița, SCIV, XIII, 2, 1962, 273-284.

Pârvan, V., La «statue-menhir» de Hamangia, Dacia, II, 1925, 422-429.

Radu, V., Studiul materialului faunistic (moluște, pești, țestoase și păsări) prelevat din nivelul Hamangia III de la Cheia, Pontica 41, 2008, 57-64.

Reingruber, A., Absolute and Relative Chronology in the Lower Danube Area During the $5^{\text {th }}$ Millenium BC, în Hansen, S., Raczky, P., Anders, A., Reingruber, A. (eds.), Neolithic and Copper Age Between the Carpathians and the Aegean Sea: Chronologies and Technologies from the $6^{\text {th }}$ to the $4^{\text {th }}$ Millennium BCE, Archäologie in Eurasien, 31, 2015, 301-324.

Tornero, C., Bălășescu, A., Ughetto-Monfrin, J., Voinea, V., Balasse, M., Seasonality and season of birth in early Eneolithic sheep from Cheia (Romania): methodological advances and implications for animal economy, Journal of Archaeological Science, 40, 2013, 4039-4055.

Voinea, V., Funeral rites in the Hamangia culture: animal sacrifices, Sprawozdania Archeologiczne, 62, 2010, 65-91.

Voinea, V., Un nou simbol Hamangia, Studii de Preistorie, 7, 2010, 45-59.

Voinea, V., Dobrinescu, C., Așezarea Hamangia III de la Cheia. Campaniile 20002001, Pontica, 35-36, 2002-2003, 9-22.

Voinea, V., Neagu, G., Ceramica Hamangia III, Pontica, 39, 2006, 9-34.

Voinea, V., Neagu, G., Archaeological research at Hamangia III settlement from Cheia (2004-2008), Pontica, 41, 2008, 9-34.

Voinea, V., Dobrinescu, C., Neagu, G., Bălășescu, A., Radu, V., The Hamangia settlement at Cheia, Constanța county, Romania, The European Archaeologist (TEA), nr. 26, winter 2006/2007, 2007, 10-11.

Voinea, V., Neagu, G., Radu, V., Spondylus shell artefacts in Hamangia cultures, Pontica, 42, 2009, 9-25.

Voinea, V., Grigoruță, O., Cărpuș, C., Hard animal material adornements discovered in Hamangia settlement from Cheia/Podoabe din materii dure animale descoperite în așezarea Hamangia de la Cheia, în Mărgărit, M., Le Dosseur, G., Averbouh, A., (eds.), Exploatation of hard animal materials during the Neolithic and Chalcolithic/O privire asupra exploatării materiilor dure animale de-a lungul Neoliticului și Calcoliticului, Proceedings of the GDRE Prehistos Work-Session, Târgoviște, 5-9 november 2013, Editura Cetatea de Scaun, Târgoviște, 2014, 101-136. 


\section{LISTA ILUSTRAȚIILOR}

Figura 1. Harta generală a siturilor neolitice și calcolitice studiate în zona Baia în cadrul „mission archéologique Danube" și a proiectului franco-român IRP-GOCHE C L. Carozza.

Figura 2. Poziția siturilor cercetate de Dumitru Berciu pe o hartă actuală a malului lagunei Razim.

Figura 3. Planul general al săpăturilor realizate de Dumitru Berciu la Ceamurlia de Jos (după Berciu 1966).

Figura 4. Distribuția cronologică a celor patru eșantioane datate pentru așezările de la Ceamurlia de Jos și BaiaGolovița.

Figura 5. Baia-Golovița, material arheologic descoperit în groapa E (Gr E); desen și DAO de L. Carozza.

Figura 6. Ceamurlia de Jos, material arheologic din groapa 3 din profilul II (Pr II, Gr 3); desen și DAO de L. Carozza

Figura 7. Ceamurlia de Jos, material arheologic din secțiunea VII (SVII, adâncime 1,1 m); desen și DAO de L. Carozza.

Figura 8. Secvența cronologică Hamangia realizată în funcție de datele radiocarbon înregistrate în așezările de la Ceamurlia de Jos, Baia-Golovița și Cheia.

Figura 9. Secvența crono-culturală Hamangia/Boian pentru nordul Dobrogei realizată în funcție de datele radiocarbon din câteva situri reprezentative.

Figura 10. Amplasarea presupusă a tell-ului Baia „Boruz” pe harta topografică 1-5000 din 1970; DAO L. Carozza.

Figura 11. Distribuția stratigrafică a materialului ceramic calcolitic individualizat de Dumitru Berciu în timpul săpăturii din 1961: (a) distribuția pe baza cotelor altimetrice notate în timpul săpăturii; (b) distribuția corectată în funcție de paleo-topografia presupusă a tell-ului; DAO L. Carozza.

Figura 12. Distribuția numărului de forme caracteristice înregistrate de Dumitru Berciu în timpul săpăturii din 1961, în așezarea-tell de la Baia „Boruz”; DAO L. Carozza.

Figura 13. Distribuția numărului de fragmente ceramice pictate cu grafit înregistrate de Dumitru Berciu în timpul săpăturii din 1961, în așezarea-tell Baia „Boruz”; DAO L. Carozza.

Figura 14. Exemplu de prezentare stratigrafică a materialului ceramic înregistrat de Dumitru Berciu în timpul săpăturii din 1961, în așezarea-tell de la Baia „Boruz”, caroul 5; desen S. Ailincai / DAO L. Carozza.

LAURENT CAROZZA,

CNRS, UMR 5602 Géographie de l'Environnement (Toulouse) - IRP GOCHE

CRISTIAN MICU, Institut de recherche EcoMuseal „Gavrilă

Simion" (Tulcea) - IRP GOCHE

ADRIAN BĂLĂȘESCU, Institut d'Archéologie „Vasile Pârvan”, Académie Roumaine (Bucarest) - IRP

SORIN AILINCĂI,

Institut de recherche EcoMuseal „Gavrilă

Simion" (Tulcea) - IRP GOCHE

ALBANE BURENS,

CNRS, UMR 5602 Géographie de

l'Environnement (Toulouse) - IRP GOCHE

OANA GÂZA,

„Horia Hulubei” National Institute of Physics and Nuclear Engineering - IFIN-HH

CRISTIAN MĂNĂILESCU,

„Horia Hulubei” National Institute of Physics and Nuclear Engineering - IFIN-HH 